Brit. F. vener. Dis. (1970) 46, 278

\title{
Evaluation of a modified FTA-ABS test
}

\section{Multispot FTA-ABS}

\author{
P. O'NEILL, ${ }^{1}$ G. D. JOHNSON, ${ }^{2}$ aND C. S. NICOL ${ }^{3}$
}

From the Department of Pathology, Lambeth Hospital, Brook Drive, London, S.E.11, the M.R.C. Rheumatism Unit, ${ }^{2}$ Canadian Red Cross Memorial Hospital, Taplow, Maidenhead, Berks., and the Venereal Diseases

Department, ${ }^{3}$ St. Thomas's Hospital, London, S.E.1.

In this report we describe a modification of the Fluorescent Treponemal Antibody Absorption Test (FTA-ABS) (Hunter, Deacon, and Meyer, 1964).

The work involved in processing immunofluorescent tests has probably discouraged the adoption of the FTA-ABS as a routine screening procedure. This difficulty will resolve when an automated immunofluorescent test becomes available. Meanwhile we have adapted to the FTA-ABS test a semi-automatic technique developed by us for processing immunofluorescence tests of all types (O'Neill and Johnson, 1970). The essential feature of the Multispot FTA-ABS technique is the testing of up to 22 sera on one standard microscope slide. Test areas are isolated one from another by a coating of water-repellent material.

Part I of this report describes the technique of the multispot FTA-ABS test. In part II we report results on 1,897 unselected sera screened by Reiter protein complement-fixation test (RPCFT), tests for reagin, and the multispot FTA-ABS test. Cases of unsuspected treponemal disease brought to light by the multispot FTA-ABS screen are described, and the use of the test for large-scale screening is discussed.

\section{Part I Technique of the multispot FTA-ABS test}

(1) PREPARATION OF COATED SLIDES

Precision glass microscope slides $0.8-1 \mathrm{~mm}$. thick are alcohol washed. Using a syringe and 25 gauge needle, 12 or 22 small $(1 \mathrm{~mm}$.) drops of glycerin are deposited in two rows on each slide. Alternatively, a glycerin dispenser designed for this purpose may be used (O'Neill and Johnson, 1970). Slides are then thoroughly sprayed with an aerosoldispensed preparation of a polymer of tetrafluoroethylene (PTFE) containing a bonding agent. ${ }^{\star}$ They are then rinsed under a running tap to remove glycerin, polished

Received for publication October 4, 1969.

A shortened version of this report was presented at the meeting of the M.S.S.V.D. in Budapest on June 16, 1969.

Correspondence to Dr. C. S. Nicol, Lydia Department, St. Thomas's Hospital, London, S.E.1.

*Fluoro Glide, Chemplast. Inc., N.J., obtainable from MarshallHowlett Ltd., 44 Tower Hill, London, E.C.3. dry, and stored. The areas protected by glycerin remain uncoated by Teflon and are the sites of the antigen spots. The PTFE coating between the slides is water-repellent and prevents the closely spaced serum drops from running together during the test. PTFE coating of slides has been described by Goldman (1968).

\section{(2) PREPARATION OF ANTIGEN}

Lyophilized Nichols strain Treponema pallidum (obtained from Baltimore Biological Laboratories) was reconstituted as directed with $1 \mathrm{ml}$. distilled water. Care was taken to mix the reconstituted reagent thoroughly, using a syringe and fine needle ( 25 gauge). Using the same syringe and needle, one drop of antigen suspension was deposited on each clear glass spot of a multispot PTFE-coated glass microscope slide. Each drop was then carefully sucked back into the syringe, and the remaining very thin film of antigen material was allowed to dry and then fixed by immersion of the slide in acetone for 10 minutes. In this way it was possible to prepare more than 1,000 antigen spots from $1 \mathrm{ml}$. lyophilized antigen. Reconstituted antigen may be left at $4^{\circ} \mathrm{C}$. for 24 hours if it cannot all be used up in one day. Antigen slides are stored at $-20^{\circ} \mathrm{C}$. in dry airtight containers.

On several occasions during this trial fresh (nonlyophilized) Nichols strain $T$. pallidum (kindly supplied by Dr A. E. Wilkinson) was used as antigen. Spots were prepared and fixed as described above. The performance of treponemes from these two sources was identical and they both stored well, acetone fixed, at $-20^{\circ} \mathrm{C}$. When retested after 6 to 12 months' storage, organisms from both these sources gave correct titres with standard control sera.

We have tried out, but did not use in this trial, treponemes from other sources. Some of these were found unsatisfactory as antigen in that they gave low titres with control sera, did not store satisfactorily on slides at $-20^{\circ} \mathrm{C}$., or (in one case) reacted only very weakly with IgM antibody. We believe it is of the greatest importance that antigen should be thoroughly evaluated before use in the test. This point is also made by Király, Jobbágy, and Mecher (1965).

Fixation of antigen in 10 per cent. methanol is preferred by some workers (Tuffanelli, Wuepper, Bradford, and Wood, 1967; Roberts, Miller, and Binnings, 1968). We agree that methanol fixation gives a cleaner preparation, but our experience suggests that methanol-fixed smears store less well at $-20^{\circ} \mathrm{C}$. than acetone-fixed material. 
(3) PREPARATION OF SERA

Serum was separated aseptically and stored at $4 \mathrm{C}$. for up to 7 days before testing. Longer storage was necessary in some instances. In these cases serum was frozen in 0.25 $\mathrm{ml}$. aliquots and held at $-20^{\circ} \mathrm{C}$. until tested. Sera were never repeatedly frozen and thawed.

Heating at $56 \mathrm{C}$. for $30 \mathrm{~min}$. to inactivate complement was found to be unnecessary during the course of this investigation. A series of forty parallel tests performed on sera with and without inactivation gave identical results. However, for the sake of uniformity, all results reported here were obtained on previously inactivated sera.

\section{(4) TEST PROCEDURE}

This consists of two stages:

(a) Reaction of sorbent-diluted serum with treponemal antigen.

(b) Exposure of serum-treated antigen spots to fluorescein-conjugated anti-human globulin (conjugate).

The sorbing reagent used was supplied by Baltimore Biological Laboratories.

(a) Sera are lined up serially in groups of ten or twenty corresponding to the number of antigen spots on each slide. Two spots on each slide are left free for control sera. Each serum in turn is quickly diluted 1 in 5 in sorbent $(0.02$ to $0.08 \mathrm{ml}$. using disposable '50-dropper' Pasteur pipettes) and a small drop of the resulting dilution is placed over the corresponding antigen spot. Finally the two control spots are overlaid with correspondingly diluted strongly-reactive and weakly-reactive sera. To load a 22-spot slide in this fashion takes about 10 minutes.

An absorption control is included in each batch of tests. This consists of a serum with known non-specific activity

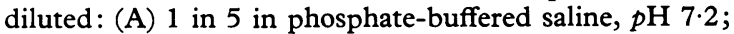
and (B) 1 in 5 in the current batch of sorbent.

The loaded slide is left in a moist chamber at room temperature for $30 \mathrm{~min}$. Serum drops are then washed off one by one with a fine jet of buffered saline from a wash bottle. Undiluted serum must obviously not be allowed to mix or to run over adjacent antigen spots. However, this tendency is counteracted by the water-repellent coating between the antigen spots. After initial washing slides are immersed in phosphate buffered saline for 10 minutes.

(b) Slides are removed from buffered saline and shaken to remove excess moisture; the back, edges, and midline of the slide are gently wiped with absorbent tissue. Fluorescent anti-human globulin conjugate at working dilution is then spotted on, one small drop to each antigen spot. Drops of conjugate may coalesce, but this does not matter. Slides are then incubated in the moist chamber for a further 20 to $30 \mathrm{~min}$. This time must not be exceeded. They are then rinsed off with buffered saline and finally immersed in buffered saline for $10 \mathrm{~min}$. Mounting is carried out as follows: slides are shaken free of excess buffer, a tiny drop of buffered glycerin is placed over each antigen spot, and the slide covered with a $22 \times 70 \mathrm{~mm}$. coverslip. The Figure shows two mounted multispot slides.

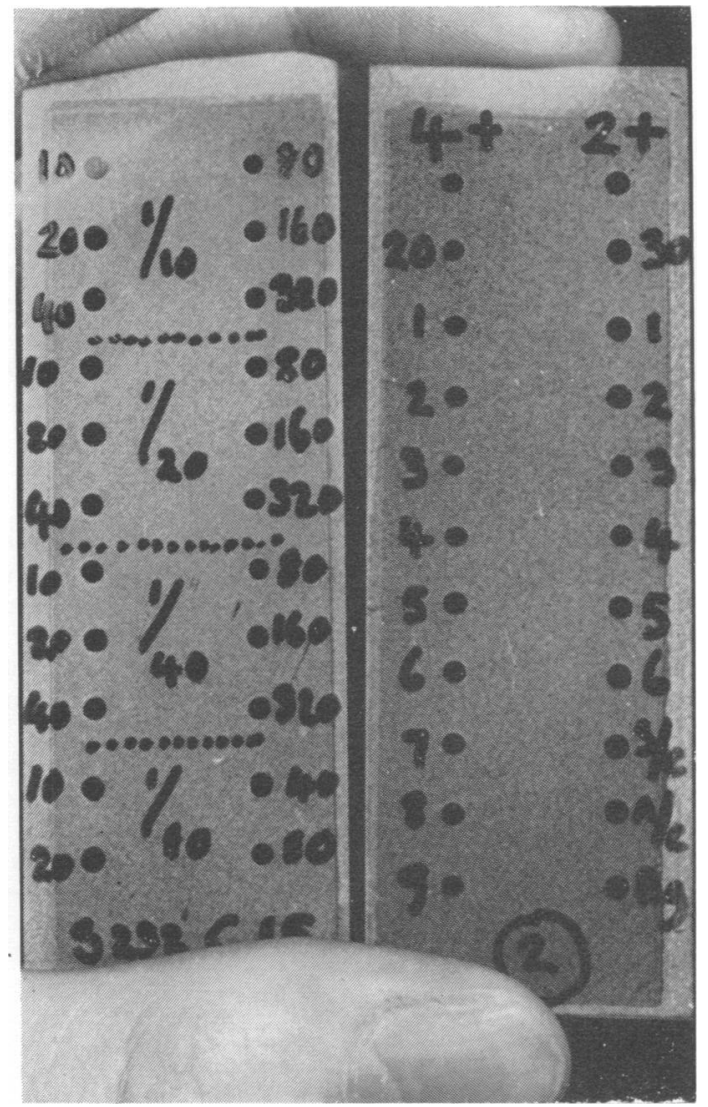

FIGURE Two mounted 22-spot multispot slides

\section{(5) FLUORESCENT CONJUGATES}

The screening tests were carried out with specific anti-IgG conjugates; for the evaluation of treponemal preparations a monospecific anti-IgM reagent was also employed. Antisera prepared in rabbits and sheep to human immunoglobulins were conjugated with fluorescein isothiocyanate (British Drug Houses) at $24 \mathrm{C}$. following the procedure described by McKinney, Spillane, and Pearce (1964). Immunoglobulin specificity was established by immunoelectrophoresis of the antisera and also by testing the performance of the conjugates in model systems as previously described (Johnson, Beutner, and Holborow, 1967). Only reagents thus found to be monospecific were employed in the study. Working dilutions were based on block titration of the conjugates against known treponemereactive sera; twice the lowest concentration of conjugate that gave maximum obtainable titre for the test serum was employed-1:30 to $1: 80$ for anti-IgG conjugates and rather less dilution in the case of anti-IgM reagents.

\section{(6) SEMI-AUTOMATIC TECHNIQUE FOR SETTING UP FTA-ABS} TEST

During the later part of this trial, sampling and diluting of sera was carried out by the semi-automatic technique de- 
scribed by us elsewhere (O'Neill and Johnson, 1970). Sera are sampled and diluted twelve at a time, and the dilutions deposited simultaneously, on a 12-spot coated slide, using a simple device operated by mouth suction. Specimens are taken in the clinic into $13 \mathrm{~mm}$. external diameter disposable polystyrene tubes, and sampling takes place directly from these. Recently, tests on heparinized plasma have been carried out in parallel with tests on serum. Fifty samples compared in this way have given identica results on serum and plasma; however, plasma is preferable for ease of handling.

Using the semi-automatic technique, setting up time for 120 tests is approximately 45 minutes.

\section{(7) READING RESULTS}

Tests were read by blue light fluorescence, usually on a Reichart Zetopan microscope with HBO 200 light source We found the best filter combination, with this ligh source, to be exciter filter $3 G 12 / 2 \mathrm{~mm}$. with barrier filter GG14, but several other combinations are suitable. With the iodine quartz light source we found Gillet and Siebert's 'Turner' interference filter, giving 85 per cent. transmission at $485 \mathrm{~mm}$. very satisfactory.

Fluorescence was graded and reported as shown in Table I.

TABLE I Reporting of Multispot FTA-ABS results

\begin{tabular}{ll}
\hline Degree of fluorescence & Test reported as \\
\hline Strong & Reactive \\
Moderate & Reactive \\
Weak & Weakly reactive \\
Very weak & Doubtful-repeat advised \\
Organisms vaguely visible & Non-reactive \\
Organisms invisible & Non-reactive \\
\hline
\end{tabular}

\section{Part II Application of the multispot FTA-ABS test as a screening procedure}

(1) PATIENTS STUDIED

These were consecutive unselected attenders at a venereal disease clinic on randomly chosen days:

(a) Patients coming for the first time, either on their own initiative, or referred by G.Ps, hospital departments, or contact tracers;

(b) Patients re-attending with previously diagnosed or suspected venereal disease.

Places of origin are represented in the following percentages: United Kingdom and Eire 64 per cent.; other European countries 6 per cent.; Jamaica 19 per cent.; other West Indies 3 per cent.; African countries 3 per cent.; other countries 5 per cent.

\section{(2) TESTS PERFORMED}

All attenders are given a Wassermann test (CWR) with Maltaner cardiolipin antigen, and a Reiter protein complement-fixation test. In addition selected patients have a quantitative Price's Precipitation Reaction (PPR) per- formed. These are usually patients undergoing treatment for syphilis or new patients in whom syphilis is suspected.

The patients in this series all had in addition a multispot FTA-ABS test, as described above. This was performed on an aliquot of serum collected from the clinic laboratory before the results of routine serology were known, and taken to another hospital one mile distant where the test was carried out. The only information available at the time of the FTA-ABS testing was the laboratory serial number of each serum. The identity of patients and results of previous tests were not known. All FTA-ABS tests were performed and read by one observer.

\section{(3) RESULTS}

1,897 sera were tested. Tables II to VII compare the results obtained in the clinic laboratory using the RPCFT, CWR, and PPR with the results of the multispot FTAABS test: to simplify presentation, CWR and PPR results have been grouped together and are referred to jointly as tests for reagin. Tables VI and VII give details of 154 patients who were non-reactive in tests at the clinic, but reactive or doubtfully reactive in the multispot FTAABS test.

\section{Multispot FTA-ABS compared with RPCFT (Table II)}

Our experience using the multispot FTA-ABS test confirms earlier reports of the reduced sensitivity of the RPCFT when compared with fluorescent antibody techniques (Wilkinson and Rayner, 1966; Stevens, Boylan, and Memoli, 1967).

TABLE II Multispot FTA-ABS results on 315 sera reactive or doubtfully reactive in the RPCFT. 161 of these sera were also reactive in tests for reagin

Result in multispot FTA-ABS

\begin{tabular}{|c|c|c|c|c|}
\hline \multirow{2}{*}{ Result in RPCFT } & \multirow{2}{*}{ Total } & \multicolumn{3}{|c|}{ test } \\
\hline & & Reactive & Doubtful & $\begin{array}{l}\text { Non- } \\
\text { reactive }\end{array}$ \\
\hline $\begin{array}{l}\text { Reactive } \\
\text { Doubtfully reactive } \\
\text { Non-reactive }\end{array}$ & $\begin{array}{r}225(115)^{\star} \\
90(46)^{\star} \\
1582\end{array}$ & $\begin{array}{r}224 \\
76 \\
133\end{array}$ & $\begin{array}{r}0 \\
6 \\
70\end{array}$ & $\begin{array}{r}1 \\
8 \\
1379\end{array}$ \\
\hline
\end{tabular}

*Numbers in brackets indicate sera which were reactive also in tests for reagin

Of the 1,897 sera tested, 225 (11.8 per cent.) were reactive in the RPCFT, with or without additional reagin activity. All but one of these 225 were positive also in the multispot FTA-ABS test. The exception was a 19-year-old English girl in whom neither history nor clinical findings suggested a diagnosis of venereal disease, and in whom the treponemal immobilization test (TPI) was negative. Subsequently all serological tests became negative, and this incident was regarded as an acute biological false positive (BFP) reaction. Among 1,582 RPCFT negative sera were 133 giving 
a positive multispot FTA-ABS test, and a further seventy giving a doubtful FTA-ABS test. These are discussed further when Tables IV to VI are considered.

\section{FTA-ABS results on RPCFT negative, reagin positive sera (Table III)}

39 sera found during clinic testing to react only in tests for reagin are shown in Table III. Details of the 33 patients concerned are shown in Table IV. Seventeen of them were positive in the FTA-ABS test, and in twelve of these a history of treponemal disease of long duration was available (15-41 years in the nine cases which could be precisely dated). Also of interest in Table IV are the four reaginpositive children of sera-positive mothers. In none of these was a positive FTA-ABS result obtained, though two were doubtfully reactive. Three of them, aged 2,3 , and 7 years, were thought clinically not to have congenital disease, and were not treated. The fourth child, aged 6 months, was clinically suspect and has since received treatment; after which the tests for reagin became negative.

TABLE IV Analysis of the 33 reagin-positive RPCFTnegative patients shown in Table III

\begin{tabular}{|c|c|c|c|}
\hline \multirow{2}{*}{ Clinical diagnosis } & \multicolumn{3}{|c|}{ Multispot $F T A-A B S$ result } \\
\hline & Reactive & Doubtful & Non-reactive \\
\hline Late syphilis & 9 & 0 & 0 \\
\hline Late congenital syphilis & 1 & 0 & 0 \\
\hline Childhood yaws & 2 & 0 & 0 \\
\hline Latent treponemal disease & 4 & 0 & 0 \\
\hline $\begin{array}{l}\text { Children of sero-positive } \\
\text { mothers }\end{array}$ & 0 & $2 \dagger$ & $2 \ddagger$ \\
\hline Acute BFP & 0 & 0 & 1 \\
\hline $\begin{array}{l}\text { Probable chronic BFP } \\
\text { (TPI negative) }\end{array}$ & 0 & 0 & 2 \\
\hline No information & 1 & 0 & $9^{\star}$ \\
\hline
\end{tabular}

*Includes three antenatal patients

tAges 7 yrs 6 mths

$\ddagger$ Ages 2 and 3 yrs

Multispot FTA-ABS results on sera negative in RPCFT and tests for reagin

Table $\mathrm{V}$ gives multispot FTA-ABS results on 1,537 sera found negative in all tests at the clinic laboratory.
TABLE $\mathrm{v}$ Multispot FTA-ABS results on 1,537 sera non-reactive in $R P C F T$ and tests for reagin

\begin{tabular}{|c|c|c|}
\hline$F T A-A B S$ results & No. of tests & No. of patients \\
\hline $\begin{array}{l}\text { Reactive } \\
\text { Doubtfully reactive } \\
\text { Non-reactive }\end{array}$ & $\begin{array}{r}112 \\
68 \\
1,357\end{array}$ & $\begin{array}{l}86 \\
62\end{array}$ \\
\hline Total & 1,537 & \\
\hline
\end{tabular}

The findings here are particularly relevant. Only 1,357 sera $(88.3$ per cent. of 1,537$)$ were FTA-ABS negative; $112(7 \cdot 3$ per cent.) were reactive in the multispot FTA-ABS test, and 68 (4.4 per cent. doubtfully reactive. Details of the 86 patients who contributed the 112 reactive sera are shown in Table VI. Although 46 of these patients were already known to the clinic as cases of treponemal disease, and a further three were under surveillance as contacts at the time of testing, FTA screening brought to our attention forty patients in whom treponemal disease was not suspected. In thirteen of these a diagnosis of syphilis ( 5 cases) or latent treponemal disease (8 cases) was subsequently confirmed. Of the remaining 27 cases, 24 were lost to follow-up as they defaulted or could not be re-contacted; they included fifteen West Indian and five African patients without definite history or stigmata of yaws. At the time of writing, follow-up is not yet complete on three female patients of United Kingdom origin who gave unexpected positive FTA-ABS results.

TABLE VI Clinical diagnosis in 86 patients reactive in the multispot FTA-ABS test, but non-reactive in $R P C F T$ and tests for reagin

\begin{tabular}{lc}
\hline Diagnosis & No. of cases \\
\cline { 1 - 2 } Treated syphilis & 33 \\
Late latent treponemal disease & 3 \\
Neurosyphilis & 1 \\
Cardiovascular syphilis & 1 \\
Primary syphilis & 5 \\
Yaws & 15 \\
Follow-up inconclusive & 24 \\
Follow-up not yet completed & 3 \\
Infant of sero-positive mother & 1 \\
\hline \multicolumn{1}{c}{ Total } & 86 \\
\hline
\end{tabular}

TABLE III Multispot FTA-ABS results on 39 sera reactive or doubtfully reactive in tests for reagin, but non-reactive in RPCFT

Result in multispot FTA-ABS

\begin{tabular}{|c|c|c|c|c|c|}
\hline Result in tests for reagin & No. of tests & No. of patients & Reactive & Doubtful & Non-reactive \\
\hline $\begin{array}{l}\text { Reactive } \\
\text { Doubtfully reactive }\end{array}$ & $\begin{array}{r}33 \\
6\end{array}$ & $\begin{array}{r}28 \\
5\end{array}$ & $\begin{array}{r}19 \\
2\end{array}$ & $\begin{array}{l}1 \\
1\end{array}$ & $\begin{array}{r}13 \\
3\end{array}$ \\
\hline
\end{tabular}


Our results also confirm earlier reports (Wilkinson and Rayner, 1966; Colombani and Ripault, 1964; Falcone, 1968) of the persistence of FTA-reacting antibodies following adequate treatment of early syphilis. The 33 cases of treated syphilis shown in Table VI include ten patients known to have had adequate penicillin treatment early in the disease. Five of these patients were treated more than 2 years (one case more than 4 years) before testing. The possibility of persistent antibody from previous infection must be considered when interpreting positive results.

\section{Doubtful FTA-ABS reactors}

Patients in whom the only finding was a doubtfully reactive FTA-ABS test are shown in Table VII. The desirability of careful follow-up of doubtful reactors is emphasized by the fact that in three of the five cases later shown to have primary syphilis, a doubtful FTA-ABS result preceded reactivity in the RPCFT and reagin tests by 2 to 4 weeks. The possibility of suppressed treponemal infection due to the administration of antibiotics for other venereal disease must be considered when assessing doubtful results. There were eight such cases among our 62 doubtful reactors.

TABLE VII Analysis of 62 patients doubtfully reactive in the multispot FTA-ABS test and non-reactive in $R P C F T$ and reagin tests

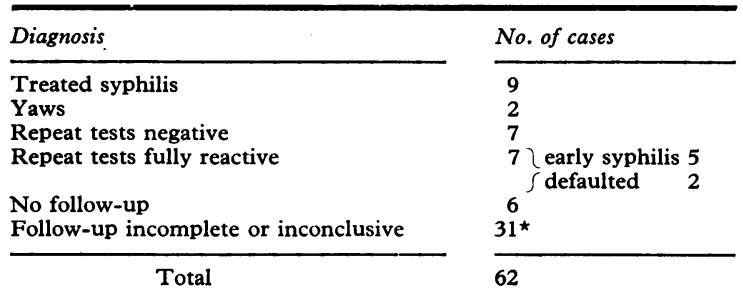

$\star$ Includes eight patients receiving antibiotics for other venereal disease and sixteen patients from yaws area but without definite history of yaws.

\section{Discussion}

We find the multispot FTA-ABS a valuable screening test. As well as being specific and very sensitive, it is easy to perform, particularly if the semi-automatic technique is employed. Moreover, the considerable economies of antigen, sorbent, and fluorescent conjugate which result from confining tests to a small area of the slide make it a relatively inexpensive immunofluorescence procedure.

It will be noted that in this trial IgG antibody alone has been detected. Aiming at clarity in the design of the trial, we chose at the outset to use a monospecific anti-IgG conjugate. Since there is evidence that antibody reacting with $T$. pallidum in the FTAABS test is mainly of the IgG class (Sartoris, Strani, Pippione, and Leigheb, 1968; Julian, Logan, and Norins, 1969), this is unlikely to lead to a significant false negative rate. However, we are currently looking into this point. Results using an anti-gammaglobulin fluorescent conjugate would probably not differ from those obtained with monospecific IgG conjugates because, at the high working dilution employed with a good anti-globulin conjugate, the antiIgM component is relatively inactive in this system.

For large-scale screening of sera we believe that the multispot FTA-ABS test is best combined with a sensitive test for reagin such as the VDRL slide test. The Rapid Plasma Reagin test might be suitable in some circumstances. Difficulties of interpretation occasionally arise with the very sensitive FTA-ABS test, particularly in circumstances in which there may be persistent antibody from previously-treated early syphilis or yaws. In these circumstances quantitative tests for reagin will clarify the situation.

\section{Summary}

The FTA-ABS test of Hunter, Deacon, and Meyer (1964) has been modified to speed up the staining procedure and to facilitate the reading of results. In particular, either ten or twenty sera plus two controls are processed on each microscope slide, instead of only two per slide as in previous methods. This enables one operator to perform 100 or more tests in a day.

1,897 screening tests have been performed so far on sera from unselected patients attending a venereal disease clinic. The results agree with those of previous series in which the FTA-ABS has been compared with other serological tests for syphilis. In addition, because the test was used for screening, treponemal disease was detected in thirteen patients in whom no other clue to this diagnosis was given.

We thank Mr A. H. Stone for technical assistance and Miss Irene Tappenden for valuable help in the preparation of serum samples.

Multispot slides, presprayed, and the diluting equipment required for the semi-automatic technique are obtainable from: Shandon Scientific Co., 65 Pound Lane, Willesden, London, N.10.

\section{References}

Colombani, J., and Ripault, J. (1964). Path. et Biol., $12,56$.

Falcone, V. H. (1968). Publ. Hlth Lab., 26, 39.

Goldman, M. (1968) 'Fluorescent Antibody Methods'. Academic Press, New York

Hunter, E. F., DeAcon, W. E., and Meyer, P. E. (1964) Publ. Hlth Rep. (Wash.), 79, 410 
Johnson, G. D., Beutner, E. H., and Holborow, E. J. (1967). F. clin. Path., 20, 720.

Julian, A. J., Logan, L. C., and Norins, L. C. (1969). F. Immunol., 102, 1250.

Király, K., JobBágy, A., and MeChER, T. (1965). Bull. Wld. Hlth Org., 33, 687.

McKinney, R. M., Spillane, J. T., and Pearce, G. W. (1964). F. Immunol., 93, 232.

O’Neill, P., and Johnson, G. D. (1970) f. clin. Path., 23, 185

Roberts, M. E., Miller, J. N., and Binnings, G. F. (1968). F. Bact., 96, 1500.

Sartoris, S., Strani, G. F., Pippione, M., and Leigheb, G. (1968). Minerva derm., 43, 219.

Stevens, R. W., Boylan, J., and Memoli, A. J. (1967). Amer. F. clin. Path., 47, 408.

Tuffanelli, D. L., Wuepper, K. D., Bradford, L. L., and Wood, R. M. (1967). New Engl. f. Med., 276, 258.

WILKINSON, A. E., and RAYNER, C. F. A. (1966). Brit. F. vener. Dis., 42, 8.

\section{Évaluation d'une épreuve FTA-ABS modifiée Le 'Multispot' FTA-ABS}

\section{SOMMAIRE}

L'épreuve FTA-ABS de Hunter, Deacon, et Meyer (1964) a été modifiée pour accélerer le processus de marquage et pour faciliter la lecture du résultat. En particulier, 10 ou 20 sérums plus 2 témoins, sont examinés sur chaque lame microscopique au lieu de 2 par lame dans les méthodes précédentes. Ceci permet à un opérateur de pratiquer en un jour 100 épreuves ou davantage.

1.897 épreuves de dépistage ont été effectuées jusqu'ici sur des sérums de consultants non choisis d'une clinique vénéréolgique. Les résultats concordent avec des séries précédentes dans lesquelles le FTA-ABS avait été comparé aux autres tests sérologiques pour la syphilis. En outre, ce test ayant été utilisé pour le dépistage, il a été reconnu une affection tréponémique chez 13 malades chez lesquels il n'y avait aucun indice de ce diagnostic. 